portions of the sidewalks. Therefore, pedestrians walk on the road instead. Because of the recent growth in the numbers of vehicles, road traffic has increased. The people are less aware of the road safety issues and often violate the Motor Vehicle Act while driving on the road or walking on the sidewalk. The Indian Railway is the second largest railway in the world, and is the highest employment generating industry in the world. Several railway safety measures are violated by the passengers, staff, and others regularly. The level crossings in one area contribute the highest number of railway accidents. In addition, fire safety measures sometimes are ignored. The infrastructure facilities and the repair and maintenance of existing infrastructures are lacking. Air crashes are a serious concern in India and requires urgent attention from the authorities. Capsizing boats are another problem, which must be studied.

Conclusion: There is a need for the development of a comprehensive action plan to combat the road, rail, and air crashes. People worldwide must take this problem seriously and take appropriate action.

\begin{tabular}{|c|c|c|c|c|}
\hline Year & $\begin{array}{c}\text { Number of } \\
\text { registered } \\
\text { vehicles }\end{array}$ & $\begin{array}{c}\text { Road } \\
\text { crashes }\end{array}$ & $\begin{array}{c}\text { Persons } \\
\text { killed }\end{array}$ & $\begin{array}{c}\text { Persons } \\
\text { injured }\end{array}$ \\
\hline $\mathbf{1 9 7 0}$ & 1,401 & 114.1 & 14.5 & 70.1 \\
\hline $\mathbf{1 9 7 5}$ & 2,472 & 116.8 & 16.9 & 77.0 \\
\hline $\mathbf{1 9 8 0}$ & 4,521 & 153.2 & 24.6 & 109.1 \\
\hline $\mathbf{1 9 8 5}$ & 9,170 & 207.0 & 39.2 & 163.4 \\
\hline $\mathbf{1 9 9 0}$ & 19,152 & 282.6 & 54.1 & 244.1 \\
\hline $\mathbf{1 9 9 5}$ & 30,287 & 348.9 & 70.6 & 323.2 \\
\hline $\mathbf{2 0 0 0}$ & 48,857 & 391.4 & 78.9 & 399.3 \\
\hline $\mathbf{2 0 0 1}$ & 54,991 & 394.8 & 80.0 & 382.7 \\
\hline
\end{tabular}

Table 1-Road traffic crashes in India (in thousands; This does not include data from Bihar and 14 districts of UP, due to unavailability; Source: Road Safety Cell, Ministry of Road Transport and Highways; This is the registered figure, but a large number of crashes are not included because both the deaths and the accidents were not registered with the Police Authority; Road infrastructure currently is developing very rapidly in India. Several Highways are being developed, and a large number of new cars and other vehicle populations are coming into the market, which increases the road accident vulnerability; Train accidents, boats capsizing, and air crashes are not included.)

Keywords: accidents; air; evaluation; India; road; safety; traffic; trains; vehicles

Prebosp Disast Med 2005;20(2):s68-s69

Getting Beyond the Physician-Centered Response to Biological Warfare and Infectious Disease: Physicians Are Not the Only "First Responders"

M. Hopmeier; ${ }^{1}$ T. Davis; ${ }^{2}$ C. Lee, ${ }^{1}$ J. Lowell, ${ }^{3}$ B. Tadmor; ${ }^{4}$

C. Conway-Welch ${ }^{5}$

1. Unconventional Concepts, Inc., USA

2. Emory University School of Medicine, USA

3. US Department of Homeland Security, USA

4. Cerberus Enterprises, LLC, USA

5. Vanderbilt University Medical Center, USA

The majority of systems, training, and preparedness for biowarfare and epidemic in the United States today are focused on the idea that the physician will not only be the principal, but the first and almost sole responder, to any major medical crisis. This is simply not the case. Based on past experience (ranging from various outbreaks of emerging disease to anthrax), it was found that medical professionals, non-medical professionals, and volunteers provided a far greater proportion of response than physicians. Indeed, once past the earliest stage of detection and diagnosis, the role of the physician as "first responder" is reduced significantly. Consider the classic example of smallpox. After the first diagnosis, the entire medical system will shift drastically so that response is no longer dependent on the physician as a primary medical advisor. Instead, the focus will shift towards population treatment with physicians acting as managers and troubleshooters, no longer first responders or diagnosticians.

Health care has evolved and developed over thousands of years to create an aura around the concept of "physician centrism," in which doctors are considered the key arbiter of life and death and provider of medical aid. In today's world of complex disasters, physician-centered response to medical events is no longer practical, possible, or even desirable. Also, the technological advancement of hospitals and hospital-trained physicians make it less likely that all physicians will be ready and adaptable to provide treatment in an uncontrolled and basic disaster environment.

As a whole, modern societies have an increased understanding of medicine and access to medical references. Also, the advent and wide availability of medical technologies, such as automated external defibrillators (AEDs) and blood pressure cuffs to monitor glucose levels have increased the population's capacity to care for and monitor themselves. But more importantly, modern healthcare systems have diversified to where medical service is provided by a variety of professionals other than physicians.

This presentation will address some of these issues and present a different approach to preparedness, namely one that relies more heavily on the diverse array of assets expected to be available rather than focusing preparedness on the very skilled, but low availability, asset of the physician.

Keywords: disaster; emergency; first responder; hospital; physician; professional; society; technology

Prebosp Disast Med 2005;20(2):s69

\section{Survey of the Medical Needs and Living Conditions in the 2003 Iran Earthquake}

K. Nakata

Nippon Medical School, Japan

Objectives: To identify serious cases and to determine the sanitation conditions following the earthquake in Bam, Iran from the acute to the sub-acute phase.

Methods: The Japan Disaster Relief (JDR) medical team surveyed 15 refugee households ( 75 persons total). The medical team asked questions regarding the health, water, and sanitation conditions.

Results: The main problems were respiratory disease $(6$ cases) and trauma ( 4 cases), but not serious injuries. There was one case of psychological stress. Public health conditions were fairly well maintained, with bottled water avail- 